\title{
Hydrogen sulfide plasma passivation of gallium arsenide
}

\author{
J. S. Herman and F. L. Terry, Jr. \\ Center for High Frequency Microelectronics, Electrical Engineering and Computer Science Department, \\ University of Michigan, Ann Arbor, Michigan 48109-2122
}

(Received 23 October 1991; accepted for publication 25 November 1991)

Improvement in the electrical properties of the GaAs surface has been accomplished using a room-temperature hydrogen sulfide plasma. The surface has then been protected by a $300^{\circ} \mathrm{C}$ plasma enhanced chemical vapor deposition (PECVD) $\mathrm{SiO}_{2}$ film. This treatment is highly reproducible due to computer control of process parameters and long-lasting due to the $\mathrm{SiO}_{2}$ cap. Improved $C-V$ characteristics were observed, showing interface trap densities in the high $10^{11} \mathrm{~cm}^{-2} \mathrm{eV}^{-1}$ range. Photoluminescence (PL) measurements on the sulfided samples showed increased intensity over the untreated samples.

The poor quality of the native oxide of GaAs has made surface passivalion extremely challenging and necessitated the use of deposited insulators. Unlike the well-behaved $\mathrm{Si}^{-\mathrm{SiO}_{2}}$ interface, the high density of surface states at the dielectric-GaAs interface results in Fermi-level pinning ${ }^{1}$ which inhibits device performance. ${ }^{2,3}$ A well passivated surface with a low interface state density is desirable in the development of a viable metal-insulator-semiconductor (MIS) technology, as well as for the passivation of other III-V devices, such as heterojunction bipolar transistors (HBT).

Recently, there have been many reports of dramatic improvements using sulfur as a surface treatment. The original application method was a spin-on $\mathrm{Na}_{2} \mathrm{~S}$ solution, ${ }^{4,5}$ but $\left(\mathrm{NH}_{4}\right)_{2} \mathrm{~S}$ applied through immersion has shown better performance by being more durable and exhibiting less leakage current in $p-n$ diodes. ${ }^{6-8}$ While there have been remarkable improvements in surface recombination velocity ${ }^{5}$ and HBT performance, ${ }^{4,9}$ there have been some problems as well, such as poor reproducibility and aging.

In this letter we will describe a new technique using a room-temperature $\mathrm{H}_{2} \mathrm{~S}$ plasma followed by a higher temperature $\left(300^{\circ} \mathrm{C}\right)$ plasma enhanced chemical vapor deposition (PECVD) $\mathrm{SiO}_{2}$ film. There are several advantages to plasma sulfidation over conventional wet chemical treatments. First, there is a high degree of reproducibility, since all the process parameters such as gas flow, chamber pressure, treatment time, and if power are computer controlled. Second, the sulfidation and subsequent $\mathrm{SiO}_{2}$ deposition are performed in the same chamber, so there is no exposure to air between the two treatments. Third, this is a long lasting treatment, since the $\mathrm{SiO}_{2}$ cap prevents air degradation of the sulfide layer.

The samples used in this study were commercially available MOCVD grown $n$-type (100) GaAs epitaxial layers $2 \mu \mathrm{m}$ thick doped to $1 \times 10^{15}$ on $n^{+}$substrates. They were degreased in hot TCA, acetone, IPA, and blown dry in $\mathrm{N}_{2}$, then etched in $\mathrm{HCl}: \mathrm{H}_{2} \mathrm{O}(1: 1)$ to remove the native oxides, rinsed in DI water and blown dry in $\mathrm{N}_{2}$. After etching they were promptly loaded into the PECVD chamber which was immediately pumped down and purged with argon. The PECVD reactor is a parallel plate SEMI group model MPB 1000 operating at $13.56 \mathrm{MHz}$. It is a direct plasma configuration, with the samples exposed to the plasma.

The room-temperature $\mathrm{H}_{2} \mathrm{~S}$ plasma treatments were performed at $200 \mathrm{~m}$ Torr for durations of 1-20 min. The temperature was then raised to $300^{\circ} \mathrm{C}$ under an argon flow and $100 \mathrm{~nm}$ of high quality $\mathrm{SiO}_{2}$ (Ref. 10) were deposited from silane, nitrous oxide, and helium using a process described elsewhere. ${ }^{11}$ The longer $\mathrm{H}_{2} \mathrm{~S}$ treatment times should not result in thicker sulfide layers, since excess sulfur on the wafer should sublime away as the temperature was raised above $110^{\circ} \mathrm{C} .{ }^{12}$ However, the longer sulfidation times did result in thinner $\mathrm{SiO}_{2}$ films, as shown in Fig. 1. We believe this is due to excess sulfur remaining on the unheated chamber walls, which then consumed reactant gases and introduced a delay in $\mathrm{SiO}_{2}$ formation. Similar problems were observed when high-temperature $\left(300^{\circ} \mathrm{C}\right)$ sulfide treatments were attempted. Two minutes was selected as the sulfidation time, as this sufficiently coated the wafer with sulfur without unduly affecting the $\mathrm{SiO}_{2}$ film.

Samples for $C-V$ measurement were patterned on the front with aluminum pads and metallized on the back with a Ni/Ge/Au ohmic contact. Results of high-frequency $C$ $V$ measurements are shown in Fig. 2. The control sample exhibits peculiar kinks in the data, while the sulfided sample shows a very smooth and continuous plot, although with significant hysteresis. A Terman analysis ${ }^{13}$ of the sulfided sample's forward curve yields a mid-gap trap density

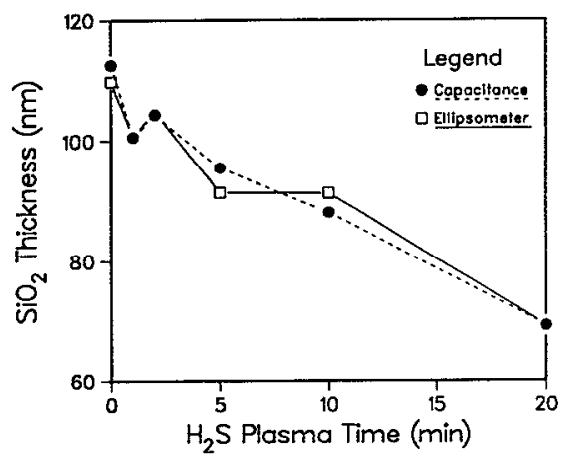

FIG. 1. Variation of $\mathrm{SiO}_{2}$ film thickness with $\mathrm{H}_{2} \mathrm{~S}$ plasma treatment time, as measured with single wavelength ellipsometry $(632.8 \mathrm{~nm})$ and oxide capacitance. 

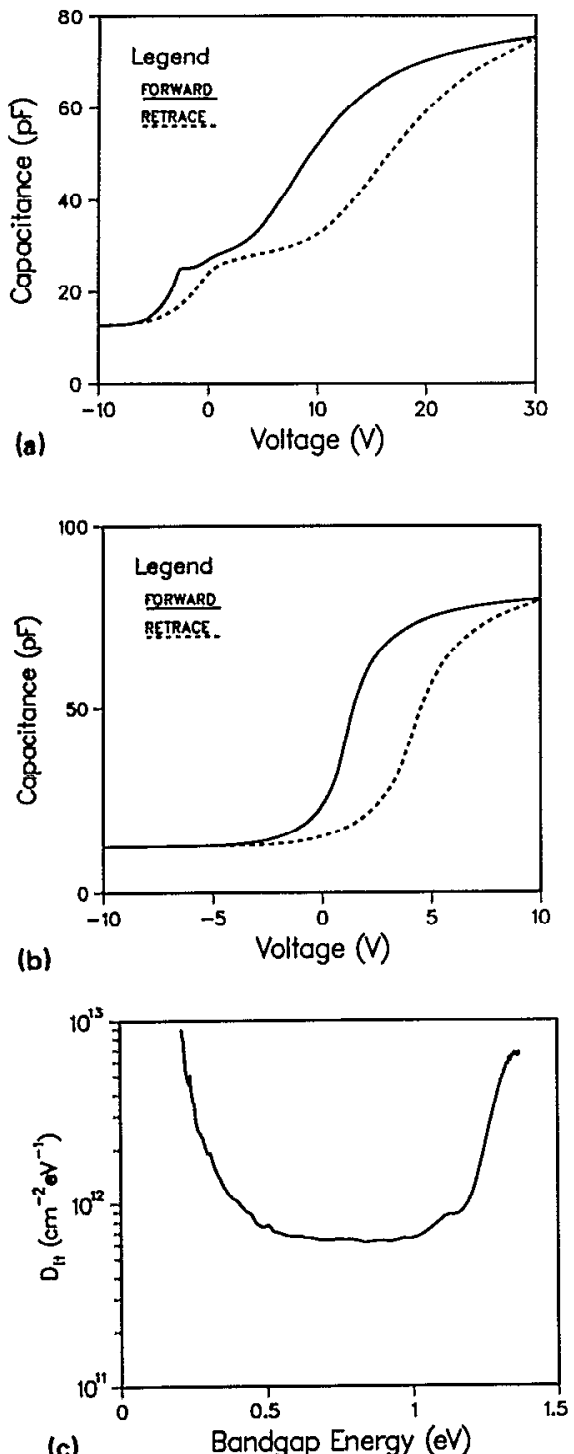

(c)

Bandgap Energy (eV)

FIG. 2. C.V characteristics of $\mathrm{SiO}_{2}$ on $\mathrm{GaAs}$. (a) Control sample with no $\mathrm{H}_{2} \mathrm{~S}$ treatment, (b) sulfided sample with $2 \min \mathrm{H}_{2} \mathrm{~S}$ plasma treatment, (c) trap distribution of the sulfided sample's forward curve calculated using Terman's method.

in the high $10^{11} \mathrm{~cm}^{-2} \mathrm{eV}^{-1}$ range. There are several possible explanations for the hysteresis, such as reoxidation of the surface from the reactive oxygen of the $\mathrm{SiO}_{2}$ film, charge trapping in the sulfide compounds at the interface, or $\mathrm{SiO}_{2}$ defects produced by initial reactions with the sulfide layer. Attempts to reduce the hysteresis with an inter- mediate amorphous silicon layer between the sulfide and the $\mathrm{SiO}_{2}$ proved unsuccessful, as the $\mathrm{SiO}_{2}$ films would bubble rapidly upon subsequent heat treatment.

Photoluminescence (PL) measurements were taken at $20 \mathrm{~K}$ using the $514.5 \mathrm{~nm}$ line of an argon ion laser operating at $0.2 \mathrm{~W} / \mathrm{cm}^{2}$. Three samples were examined, a bare GaAs sample, a $\mathrm{SiO}_{2}$ on $\mathrm{GaAs}$ sample, and a sample with a 2 min sulfide treatment followed by a $\mathrm{SiO}_{2}$ cap. The $\mathrm{SiO}_{2}$ layers were thin (approximately $30 \mathrm{~nm}$ ) for the PL study.

The PL analysis consisted of comparing the peak intensity of the conduction band to valence band transition (located at $820.7 \mathrm{~nm}$ ), generally considered to scale inversely with surface state density. ${ }^{14}$ The peak intensity for the $\mathrm{SiO}_{2}$ on $\mathrm{GaAs}$ sample was slightly lower than the bare control sample, but the signal from the $\mathrm{SiO}_{2}$ capped sulfided GaAs sample was nearly twice as strong as the $\mathrm{SiO}_{2}$ on GaAs sample and stronger even than the bare sample.

In conclusion, a promising technique has been demonstrated for sulfidation of the GaAs surface that is both reproducible and long lasting. Improvements in the MIS C-V characteristics were observed, although significant hysteresis remains. Further work will be required to reduce this hysteresis, and to determine the applicability of this approach to other III-V semiconductor surfaces.

The authors would like to acknowledge W. T. Shiau for assistance with $C-V$ analysis and S. Sethi for PL measurements. This work was supported by the Army Research Office under the URI program, Contract No. DAAL03-86-K-0007.

${ }^{1}$ W. E. Spicer, P. W. Chye, P. R. Skeath, C. Y. Su, and I. Landau, J. Vac. Sci. Technol. 16, 1422 (1979).

${ }^{2}$ C. R. Zeiss, L. J. Messick, and D. L. Lile, J. Vac. Sci. Technol. 14, 957 (1977).

${ }^{3}$ L. G. Meiners, J. Vac. Sci. Technol. 15, 1402 (1978).

${ }^{4}$ C. J. Sandroff, R. N. Nottenburg, C.-J. Bischoff, and R. Bhat, Appl. Phys. Lett. 51, 33 (1987).

${ }^{5}$ E. Yablonovitch, C. J. Sandroff, R. Bhat, and T. Gmitter, Appl. Phys. Lett. 51, 439 (1987).

${ }^{6}$ M. S. Carpenter, M. R. Melloch, M. S. Lundstrom, and S. P. Tobin, Appl. Phys. Lett. 52, 2157 (1988).

${ }^{7}$ M. S. Carpenter, M. R. Melloch, and T. E. Dungan, Appl. Phys. Lett. 53, 66 (1988).

${ }^{8}$ R. S. Besser and C. R. Holms, J. Appl. Phys. 65, 4306 (1989).

${ }^{9}$ R. N. Nottenburg, C. J. Sandroff, D. A. Humphrey, T. H. Hollenbeck, and R. Bhat, Appl. Phys. Lett. 52, 218 (1988).

${ }^{10}$ J. Batey and E. Tierney, J. Appl. Phys. 60, 3136 (1986).

${ }^{11}$ J. S. Herman and F. L. Terry, Jr., IEEE Electron Device Lett. 12, 236 (1991).

${ }^{12}$ R. Iyer, R. R. Chang, and D. L. Lile, Appl. Phys. Lett. 53, 134 (1988).

${ }^{13}$ L. M. Terman, Solid-State Electron. 5, 285 (1962).

${ }^{14}$ H. C. Casey, Jr. and E. Beuhler, Appl. Phys. Lett. 30, 247 (1977). 